\title{
Comparison and Impact of Four Different Methodologies for Identification of Ambulatory Care Sensitive Conditions
}

\author{
Andreia Pinto ${ }^{1,2, *}$, João Vasco Santos ${ }^{1,2,3} \mathbb{C}^{1}$, Júlio Souza ${ }^{1,2} \mathbb{C}^{\text {, João Viana }}{ }^{1,2}$, \\ Cristina Costa Santos ${ }^{1,2}$, Mariana Lobo ${ }^{1,2}$ (D) and Alberto Freitas ${ }^{1,2}(\mathbb{D}$ \\ 1 Department of Community Medicine, Information and Health Decision Sciences (MEDCIDS), \\ Faculty of Medicine, University of Porto, 4200-450 Porto, Portugal; jvasco.santos@gmail.com (J.V.S.); \\ juliobsouza@med.up.pt (J.S.); joao.a.viana@gmail.com (J.V.); csantos@med.up.pt (C.C.S.); \\ nanalobo@gmail.com (M.L.); alberto@med.up.pt (A.F.) \\ 2 CINTESIS-Center for Health Technology and Services Research, 4200-450 Porto, Portugal \\ 3 Public Health Unit, ACES Grande Porto VIII-Espinho/Gaia, 4500-330 Porto, Portugal \\ * Correspondence: andreiapinhopinto@gmail.com
}

Received: 30 September 2020; Accepted: 30 October 2020; Published: 3 November 2020

\begin{abstract}
Ambulatory care sensitive conditions (ACSCs) are conditions for which hospitalizations are thought to be avoidable if effective and accessible primary health care is available. However, to define which conditions are considered ACSCs, there is a considerable number of different lists. Our aim was to compare the impact of using different ACSC lists considering mainland Portugal hospitalizations. A retrospective study with inpatient data from Portuguese public hospital discharges between 2011 and 2015 was conducted. Four ACSC list sources were considered: Agency for Healthcare Research and Quality (AHRQ), Canadian Institute for Health Information (CIHI), the Victorian Ambulatory Care Sensitive Conditions study, and Sarmento et al. Age-sex-adjusted rates of ACSCs were calculated by district (hospitalizations per 100,000 inhabitants). Spearman's rho, the intraclass correlation coefficient (ICC), the information-based measure of disagreement (IBMD), and Bland and Altman plots were computed. Results showed that by applying the four lists, different age-sex-adjusted rates are obtained. However, the lists that seemed to demonstrate greater agreement and consistency were the list proposed by Sarmento et al. compared to AHRQ and the AHRQ method compared to the Victorian list. It is important to state that we should compare comparable indicators and ACSC lists cannot be used interchangeably.
\end{abstract}

Keywords: ambulatory care sensitive conditions; hospitalizations; primary health care; reproducibility of results; Portugal

\section{Introduction}

Ambulatory care sensitive conditions (ACSCs) are conditions that can be typically managed at the first level of health care and for which hospitalizations can be potentially avoidable, in the sense that effective primary health care should provide an early diagnosis and proper management of chronic diseases, reducing the risk of hospitalization [1-3].

The determination of hospital admission rates for ACSCs has been increasingly used as an indicator to measure the quality and accessibility of primary health care [4-6]. The concept started to gain interest in the early 1990s in the United States (US) [1,7,8] and, over the years, many authors studied the impact of avoidable hospitalizations in different countries [9-17]. In some European countries, where access to primary health care (PHC) is universal, the concept of ACSCs is mostly applied to evaluate the quality of primary care, as it happens in Portugal, rather than to evaluate accessibility [10], which is 
more common, for instance, in the US, where health care access is not universal. Additionally, in other countries with PHC systems similar to the Portuguese system, such as Spain, Italy, France, and Finland, where there is universal health coverage, the gatekeeping function (general practitioners are the entry point to the health system and thus primary care providers coordinate referrals to hospitals and specialists) is practiced and the patient must be registered with a general practitioner; such countries have reported geographical variations in ACSC hospitalizations [16,18-20]. Distinguishing this type of variation can be crucial to identify areas that need a deeper focus and possibly further regionally or locally tailored health policies [19].

However, there is a lack of consensus regarding which conditions should be considered as ACSCs. To select the set of ACSCs that is most important to the population under study, different lists have been proposed in the literature, and the choice of the list to be used is considered one of the most important steps to estimate avoidable hospitalization rates [3,21]. ACSCs are usually defined through a consensus method, often using the Delphi method with a panel composed of experts [1,11,22-24].

The rate of ACSCs in a specific population is impacted by the list applied in the study, that is, (1) the respective coding of diseases, (2) the version of International Classification of Diseases (ICD), (3) the age group covered, (4) the exclusion criteria, and (5) research setting. Therefore, it varies between contexts [25], causing variability in the results and consequently in their interpretation. At the moment, despite the large number of ACSC lists, many countries do not have a list adapted to their specific context; in general, the choice of the list used to calculate the rates of avoidable hospitalizations is selected according to the choice of the study group.

Previous studies conducted in Portugal and France assessed the impact of using two methodological approaches to identify ACSCs. Kappa statistics for nominal scales were used to assess the agreement in the Portuguese study, and the impact between the different lists was verified graphically in the second study. Both studies verified considerable differences in rates, with poor agreement between the methods [26,27]. It is also relevant to assess whether rates computed based on different lists provide consistent measures (i.e., whether the increase or decrease of hospitalizations is observed in each list to the same extent) and, more importantly, whether they can be exchangeable. Thus, our objective was to compare the impact of ACSC rates by using different ACSC lists.

\section{Materials and Methods}

We conducted a retrospective study in order to assess and compare ACSC hospitalization rates in mainland Portugal using different lists proposed in the literature, for the period between 2011 and 2015, using the district level as the unit of analysis.

Data concerning hospital discharges from all public hospitals were provided by the Central Administration of the Health System (ACSS). Annual estimates of the resident population by district of residence and for all years of the study were extracted from Statistics Portugal [28].

A review of ACSC lists identified in the literature or in well-known organizations was performed to determine which ones could be included in this study. Afterward, we reviewed the method behind each ACSC list, including the diagnosis codes defined as ACSCs, the coding system used (International Classification of Diseases 9th revision (ICD-9) or ICD-10 codes), the inclusion and exclusion criteria (e.g., principal diagnosis or any diagnoses, age group range, exclusion of procedure codes), and the country in which the list is commonly applied or has been validated, as it is generally specific to the country's health needs and the health system itself. Since in Portugal, the discharges were coded in ICD-9-CM until 2016, we excluded all the ACSC lists defined with ICD-10 codes. Only the list proposed by Sarmento et al. (2020), which is defined in terms of the ICD-10, was converted into ICD-9-CM codes in order to be included in this study, as it was developed for the Portuguese context. The conversion was carried using the General Equivalence Mappings (GEMs) method, implemented in the R package "touch". Hence, avoidable hospitalizations were identified as ACSCs according to the set of ICD-9-CM codes defined in the lists adopted by the Agency for Healthcare Research and Quality (AHRQ) version 6.0 [13], by the Canadian Institute for Health Information (CIHI) [12], and by the 
Victorian Ambulatory Care Sensitive Conditions Study (2001-02) [29] and the list of ACSC conditions suggested by Sarmento et al. (2020), which was published very recently [30].

\subsection{AHRQ List}

The AHRQ developed the prevention quality indicators (PQIs), which are computed based on a set of codes of principal or secondary diagnosis that are related to ACSC hospitalizations. This method is well recognized and employed in several studies/countries [31-36], although it was firstly developed in the US. We applied in this study the PQI 90 Overall composite, which covers 11 diseases in the adult population ( $\geq 18$ years old). It excludes obstetric admissions; transfers from other institutions; some procedure codes; and hospitalizations for which patient information regarding sex, year of hospitalization, main diagnosis, or residence is missing.

\subsection{CIHI List}

The CIHI method encompasses only seven conditions and only chronic diseases, which are identified by principal diagnosis for patients younger than 75 years of age. Exclusions are based on some procedure codes, records with death as discharge status, and also newborns and stillbirths.

\subsection{Victorian List}

The Victorian ACSC study includes 19 conditions (acute, chronic, and immunizable diseases) that are identified mostly by principal diagnosis and some diseases through "any diagnosis". In this method, there is no exclusion for age, only for some procedure codes.

\subsection{Sarmento et al. List}

Recently, Sarmento et al. [30] performed a modified web-based Delphi panel approach to define which conditions are considered ACSCs in the Portuguese adult population context (aged 18 years or older). Experts from the most important Portuguese scientific societies (general practitioners and medicine physicians) selected the conditions by choosing a list of conditions previously identified as ACSCs in the literature that could be considered avoidable in terms of hospital admissions in Portugal. Furthermore, they had to identify other potential conditions that they considered avoidable in terms of hospital admission in Portugal despite not being identified in the previous list. The consensus level was established as 75\% after a maximum of three rounds. A core list of ACSCs that met criteria ii to iv proposed by Solberg and Weissman (clarity in the definition and coding of diagnoses; with relevance for public health, that is, a hospitalization rate of least $1 / 10,000$ population; and if the diagnosis is potentially avoidable by timely and effective ambulatory care) $[7,8]$ and an extended list with all the conditions agreed upon by the experts, even if not fulfilling the criteria proposed by Solberg and Weissman, were determined. We applied in this study the core list of Portuguese ACSCs and the conditions were identified by principal diagnosis. Exclusions based on diagnosis or procedure codes have not been defined by Sarmento et al. list. Table 1 includes the diseases that are considered sensitive to primary care and the exclusion criteria applicable in each list.

Of the 9,048.742 admission cases included in the database (2011-2015) provided by ACSS, only $5,682,688$ corresponded to episodes of hospitalization (the remaining cases refer to ambulatory episodes and thereby were excluded). Considering all hospitalizations, we only included episodes that are considered statistically valid $(n=4,426,227)$, that is, the length of stay in the hospital was at least $24 \mathrm{~h}$ or shorter than $24 \mathrm{~h}$ for patients who died, left against medical advice, or were transferred. Additionally, the episodes for which the districts are unknown, as well as admissions related to territories outside mainland Portugal were excluded from the analysis $(n=23,072)$. We also calculated the sum of all avoidable hospitalizations for the diseases that are part of each list (that is, the composite indicator of each list), such as the example of the PQI90 defined by AHRQ. 
Table 1. Inclusion and Exclusion Criteria of Each Ambulatory Care Sensitive Conditions List.

\begin{tabular}{|c|c|c|c|c|c|}
\hline & & AHRQ & CIHI & Victorian ACSC Study & Sarmento et al. \\
\hline \multirow{30}{*}{$\begin{array}{l}\text { Diseases } \\
\text { included }\end{array}$} & Diabetes & $\begin{array}{l}\mathrm{X} \text { (short- and } \\
\text { long-term) }\end{array}$ & $x$ & $x$ & $x$ \\
\hline & Uncontrolled diabetes & $x$ & & & \\
\hline & $\begin{array}{l}\text { Lower-extremity amputation } \\
\text { among patients with diabetes }\end{array}$ & $x$ & & & \\
\hline & $\begin{array}{c}\text { Chronic obstructive pulmonary } \\
\text { disease }\end{array}$ & $x$ & $x$ & $x$ & $\begin{array}{l}\text { X (and chronic } \\
\text { bronchitis) }\end{array}$ \\
\hline & Hypertension & $x$ & $x$ & $x$ & $x$ \\
\hline & Heart failure & $x$ & $\begin{array}{l}X \text { (and } \\
\text { pulmonary } \\
\text { edema) }\end{array}$ & X (congestive) & $x$ \\
\hline & Angina & & $x$ & $x$ & \\
\hline & Atrial fibrillation & & & & $x$ \\
\hline & Dehydration & $x$ & & $\mathrm{X}$ (and gastroenteritis) & $\begin{array}{c}X \text { (and } \\
\text { hydroelectrolytic } \\
\text { changes) }\end{array}$ \\
\hline & Pneumonia & $\begin{array}{l}\mathrm{X} \text { (bacterial } \\
\text { pneumonia) }\end{array}$ & & $X$ (and influenza) & $x$ \\
\hline & Urinary tract infection & $x$ & & X (pyelonephritis) & $x$ \\
\hline & Asthma & $\begin{array}{l}\mathrm{X} \text { (in young } \\
\text { adults) }\end{array}$ & $x$ & $x$ & $x$ \\
\hline & $\begin{array}{l}\text { Grand mal status and other } \\
\text { epileptic convulsions }\end{array}$ & & $x$ & $\begin{array}{l}\mathrm{X} \text { (convulsions and } \\
\text { epilepsy) }\end{array}$ & \\
\hline & Other vaccine-preventable & & & $x$ & \\
\hline & Iron deficiency anemia & & & $x$ & $x$ \\
\hline & Nutritional deficiencies & & & $x$ & \\
\hline & Perforated/Bleeding ulcer & & & $x$ & \\
\hline & Cellulitis & & & $x$ & $\begin{array}{l}X \text { (acute skin } \\
\text { infections) }\end{array}$ \\
\hline & Pelvic inflammatory disease & & & $x$ & \\
\hline & Ear, nose, and throat infections & & & $x$ & \\
\hline & Dental conditions & & & $x$ & $x$ \\
\hline & Gangrene & & & $x$ & \\
\hline & Uterine cervical cancer & & & & $x$ \\
\hline & Colorectal cancer & & & & $x$ \\
\hline & Dementia & & & & $x$ \\
\hline & Depression & & & & $x$ \\
\hline & Gastroenteritis & & & & $x$ \\
\hline & Obesity & & & & $x$ \\
\hline & $\begin{array}{l}\text { Thromboembolic venous } \\
\text { disease }\end{array}$ & & & & $x$ \\
\hline & $\begin{array}{l}\text { Voluntary termination of } \\
\text { pregnancy }\end{array}$ & & & & $x$ \\
\hline
\end{tabular}


Table 1. Cont.

\begin{tabular}{|c|c|c|c|c|c|}
\hline & & AHRQ & CIHI & Victorian ACSC Study & Sarmento et al. \\
\hline \multirow{11}{*}{$\begin{array}{l}\text { Exclusion } \\
\text { criteria }\end{array}$} & Age & $\begin{array}{l}\text { Admissions } \\
\text { younger than } \\
18 \text { years old }\end{array}$ & $\begin{array}{l}\text { Admissions older } \\
\text { than } 75 \text { years old }\end{array}$ & No age limit & $\begin{array}{l}\text { Admissions } \\
\text { younger than } \\
18 \text { years old }\end{array}$ \\
\hline & Procedure codes & $x$ & $x$ & $x$ & \\
\hline & Obstetric admissions & $x$ & & & \\
\hline & Transfers from other institutions & $x$ & & & \\
\hline & Missing gender & $x$ & $x$ & & \\
\hline & Missing year & $x$ & & & \\
\hline & Missing age & $x$ & & & \\
\hline & Missing principal diagnosis & $x$ & & & \\
\hline & Missing residence & $x$ & & & \\
\hline & Records with discharge as death & & $x$ & & \\
\hline & $\begin{array}{l}\text { Newborn, stillbirth, or cadaveric } \\
\text { donor records }\end{array}$ & & $x$ & & \\
\hline
\end{tabular}

Notes: ACSC: ambulatory care sensitive condition; AHRQ: Agency for Healthcare Research and Quality; CIHI: Canadian Institute for Health Information.

\subsection{Statistical Analysis}

A descriptive analysis was performed considering the number of hospitalizations each year and the proportion of those that are considered preventable.

For each studied list, all ACSC hospitalization rates were calculated per 100,000 inhabitants (according to the age groups required in each list) by district and year. Age- and sex-standardized ACSC hospitalization rates were calculated through direct standardization using the 2015 Portuguese population data as the reference population to overcome different age distributions across regions in Portugal (there is an older population in the inner cities and a younger population in more populated areas located on the coast), which may contribute to regional variations in the prevalence of some diseases.

We performed the same methods used recently by Santos et al. for assessing the correlation, reliability, and agreement of health expectancies [37]. Spearman's rho was calculated to assess the correlation of avoidable hospitalization rates between lists. This method provides scores that can vary between -1 and +1 , and a value of 0 means that no association exists between the variables [38]. The $95 \%$ confidence intervals (CIs) were estimated using a bootstrapping with 1000 resamples. However, the correlation only indicates the direction and degree of association between the variables, so we calculated other measures that allowed us to infer the reliability and agreement between the variables (the avoidable hospitalization rate obtained from the different lists) since two methods can be correlated without a great agreement. Thus, intraclass correlation coefficient (ICC) and information-based measure of disagreement (IBMD) were also calculated in order to study the reliability and disagreement, respectively. ICC was used to measure the reliability of the different lists (continuous variables), and the ICC estimates and 95\% CIs were calculated based on a two-way mixed-effects model, consistency definition, and average measurements. The ICC value obtained can range from 0 to 1 , with values closer to 1 indicating better reliability [39,40]. IBMD was used to evaluate the disagreement among the rates; coefficients closer to 0 indicate less disagreement among the measures, while coefficients closer to 1 indicate higher disagreement [41]. Bland and Altman [42] plots were also performed to graphically assess the average difference in the rates obtained from the different lists (the agreement), also providing information regarding the variability of rate across districts [43]. Given that rate estimates were obtained per year and district, the average difference in rates drawn for the Bland and Altman plots was determined using mixed-effect models, which can handle the repeated measures of our data. 
Analyses were performed using the RStudio Team (Boston, MA, USA), version 1.2.1335, IBM SPSS Statistics, version 26.0 (IBM Corp., Armonk, NY, USA), and Microsoft Excel, version 16.37 (Microsoft Corporation, Redmond, WA, USA).

\section{Results}

After applying the exclusion criteria, it was found that a total of 4,403,155 eligible hospitalizations occurred in the 5 years of the study. In Table 2, the number of episodes of inpatient hospitalizations in Portugal between 2011 and 2015 and the proportion of those considered avoidable are presented, for each methodology and year, according to the inclusion and exclusion criteria of each list.

Table 2. Number of Hospitalizations Per Year and Respective Proportion of Avoidable Hospitalizations by Four Distinct Lists.

\begin{tabular}{cccccc}
\hline \multicolumn{7}{c}{ Avoidable Hospitalizations, $\boldsymbol{n}(\%)$} \\
\hline Year & AHRQ & CIHI & Victorian & Sarmento et al. & Total hospitalizations \\
\hline 2011 & $87,680(9.8 \%)$ & $20,386(2.3 \%)$ & $99,002(11.1 \%)$ & $118,685(13.3 \%)$ & 893,977 \\
\hline 2012 & $91,040(10.2 \%)$ & $20,871(2.3 \%)$ & $102,349(11.5 \%)$ & $125,049(14.0 \%)$ & 890,484 \\
\hline 2013 & $94,099(10.6 \%)$ & $20,352(2.3 \%)$ & $104,580(11.8 \%)$ & $126,195(14.3 \%)$ & 884,566 \\
\hline 2014 & $93,704(10.8 \%)$ & $19,822(2.3 \%)$ & $104,477(12.0 \%)$ & $125,641(14.5 \%)$ & 867,876 \\
\hline 2015 & $95,216(11.0 \%)$ & $19,680(2.3 \%)$ & $106,594(12.3 \%)$ & $127,938(14.8 \%)$ & 866,252 \\
\hline Total & $461,739(10.5 \%)$ & $101,111(2.3 \%)$ & $517,002(11.7 \%)$ & $623,508(14.2 \%)$ & $4,403,155$ \\
\hline
\end{tabular}

Notes: AHRQ: Agency for Healthcare Research and Quality; CIHI: Canadian Institute for Health Information. Total hospitalizations were calculated considering our study exclusion criteria (the same for all lists, based on outpatient care setting, patient residence information, statistical validity).

Analyzing Table 3, it is possible to observe the age-sex-adjusted rates according to the district in 2011 and 2015. Applying AHRQ, the Victorian study, and Sarmento et al. methods, the results showed an overall increase in avoidable hospitalization rates during the 5 years of study $(6.1 \%, 5.5 \%$, and $4.4 \%$, respectively), whereas a decrease of about $4.3 \%$ was observed when applying the CIHI list. In Table 3 , districts presenting a $10 \%$ or more change between the first and last year of analysis are marked with a symbol. Almost all districts showed a rate increase across the 5 years in three out of the four lists; however, only a few displayed an increase or decrease of above $10 \%$. Only CIHI methodology showed a $10 \%$ or more decrease in the rates.

Considering the correlations between the methods, according to the calculation of the Spearman's rho (Table 4), all comparisons represented a positive correlation; that is, as one variable increases, the other variable tends to also increase. The adjusted rates calculated by the AHRQ and Sarmento et al. methods were the ones with the highest correlation $(p \geq 0.893)$, whereas the adjusted rates of the comparison regarding CIHI and Victorian methodologies presented the lowest value, particularly in 2015 ( $p=0.645)$. Low levels of association were also observed in other comparisons in which the CIHI method is present. Considering the years studied, 2013 was generally the year with the highest correlation between the studied lists, while 2015 was generally the year in which the correlations were lower.

The IBMD allowed us to make inferences about the disagreement between the different methods (Table 5). Regarding this statistical parameter, we found a greater disparity depending on the pair of lists evaluated. We observed that the pairs of lists that included the CIHI method presented a higher disagreement, as the IBMD value was closer to 1 (IBMD $>0.8$ ). AHRQ and Victorian methods were the ones that showed a smaller disagreement in the 5 years of analysis (IBMD $\leq 0.148$ ), and the values were similar over the years. The list proposed by Sarmento et al. compared to the Victorian methodology showed a greater disagreement $(\mathrm{IBMD}=0.407)$ in relation to the same list compared to the method from AHRQ $(I B M D=0.330)$. 
Table 3. Age-Sex-Adjusted Rate Per District According to Four Different Methods in 2011 and 2015 (Per 100,000 Inhabitants).

\begin{tabular}{|c|c|c|c|c|c|c|c|c|}
\hline \multirow[b]{3}{*}{ District } & \multicolumn{8}{|c|}{ Hospitalizations Per 100,000 Inhabitants } \\
\hline & \multicolumn{4}{|c|}{2011} & \multicolumn{4}{|c|}{2015} \\
\hline & AHRQ & CIHI & Victorian & Sarmento et al. & AHRQ & CIHI & Victorian & Sarmento et al. \\
\hline Aveiro & 1204.6 & 211.0 & 1060.2 & 1625.2 & 1109.0 & 199.4 & 1011.0 & 1521.3 \\
\hline Beja & 754.2 & 143.3 & 721.4 & 1087.8 & $1025.3^{*}$ & $228.6^{*}$ & $976.4^{*}$ & $1375.8^{*}$ \\
\hline Braga & 1019.6 & 185.9 & 951.7 & 1451.3 & $1217.8^{*}$ & 195.3 & 977.9 & $1617.9^{*}$ \\
\hline Bragança & 1199.0 & 262.8 & 1138.4 & 1632.3 & 1143.0 & $234.9+$ & 1109.2 & 1624.7 \\
\hline Castelo Branco & 1387.5 & 421.9 & 1543.6 & 1875.8 & 1398.5 & 423.0 & 1474.0 & 1837.6 \\
\hline Coimbra & 1435.2 & 310.8 & 1094.6 & 1867.2 & 1430.5 & $249.4+$ & 1146.1 & 1875.1 \\
\hline Évora & 767.7 & 188.9 & 697.2 & 1035.6 & 769.8 & 174.2 & $821.8^{*}$ & 1060.1 \\
\hline Faro & 984.7 & 181.6 & 796.7 & 1244.5 & 1057.5 & 197.5 & 846.4 & 1343.3 \\
\hline Guarda & 962.9 & 236.4 & 788.1 & 1391.8 & 1023.7 & $268.5^{*}$ & $867.0^{*}$ & 1518.1 \\
\hline Leiria & 1569.4 & 289.4 & 1186.6 & 2055.3 & 1548.0 & $242.6+$ & 1224.1 & 1880.3 \\
\hline Lisboa & 1194.2 & 253.0 & 1123.9 & 1572.2 & 1139.2 & 238.8 & 1149.1 & 1586.5 \\
\hline Portalegre & 1151.6 & 360.2 & 1046.7 & 1368.6 & $1292.9^{*}$ & $249.6+$ & 1048.7 & 1493.8 \\
\hline Porto & 1100.5 & 212.9 & 1098.3 & 1475.5 & 1067.0 & 210.8 & 1097.6 & 1437.7 \\
\hline Santarém & 1080.1 & 245.7 & 1132.8 & 1636.0 & $1369.1 *$ & 257.4 & 1213.4 & 1768.1 \\
\hline Setúbal & 977.4 & 187.0 & 899.7 & 1304.8 & 1038.2 & 172.6 & $1036.6^{*}$ & 1388.4 \\
\hline Viana do Castelo & 1005.6 & 211.4 & 951.7 & 1391.1 & 1081.2 & $186.0+$ & 1026.3 & 1478.3 \\
\hline Vila Real & 1384.3 & 308.6 & 1228.8 & 1853.6 & $1645.8^{*}$ & 315.2 & 1306.9 & $2124.4^{*}$ \\
\hline Viseu & 1095.5 & 236.9 & 956.4 & 1523.8 & 1157.0 & 213.9 & $1088.5^{*}$ & 1669.4 \\
\hline Mainland Portugal & 1126.3 & 247.1 & 1023.1 & 1521.8 & 1195.2 & 236.5 & 1078.9 & 1588.9 \\
\hline
\end{tabular}

Table 4. The Correlation between Lists Assessed in Terms of Spearman's Rho.

\begin{tabular}{ccccc}
\hline \multicolumn{3}{c}{ CIHI vs. AHRQ } & CIHI vs. Victorian & AHRQ vs. Victorian \\
\hline Year & $n$ & Spearman's rho [95\% CI] & Spearman's rho [95\% CI] & Spearman's rho [95\% CI] \\
\hline 2011 & 18 & $0.787[0.498 ; 0.920]$ & $0.779[0.485 ; 0.950]$ & $0.876[0.607 ; 0.975]$ \\
2012 & 18 & $0.829[0.523 ; 0.948]$ & $0.777[0.473 ; 0.923]$ & $0.798[0.509 ; 0.925]$ \\
2013 & 18 & $0.934[0.788 ; 0.983]$ & $0.938[0.796 ; 0.985]$ & $0.880[0.694 ; 0.952]$ \\
2014 & 18 & $0.761[0.386 ; 0.950]$ & $0.730[0.318 ; 0.954]$ & $0.860[0.632 ; 0.946]$ \\
2015 & 18 & $0.602[0.135 ; 0.894]$ & $0.645[0.152 ; 0.919]$ & $0.822[0.492 ; 0.937]$ \\
Overall & 90 & $0.806^{*}$ & $0.786^{*}$ & 0.861 * \\
\hline \multicolumn{7}{c}{ AHRQ vs. Sarmento et al. } & CIHI vs. Sarmento et al. & Victorian vs. Sarmento et al. \\
\hline Year & $n$ & Spearman's rho [95\% CI] & Spearman's rho [95\% CI] & Spearman's rho [95\% CI] \\
\hline 2011 & 18 & $0.893[0.667 ; 0.981]$ & $0.736[0.316 ; 0.956]$ & $0.899[0.715 ; 0.975]$ \\
2012 & 18 & $0.893[0.635 ; 0.987]$ & $0.818[0.501 ; 0.952]$ & $0.841[0.607 ; 0.960]$ \\
2013 & 18 & $0.911[0.697 ; 0.994]$ & $0.880[0.638 ; 0.960]$ & $0.874[0.672 ; 0.966]$ \\
2014 & 18 & $0.957[0.828 ; 0.994]$ & $0.816[0.534 ; 0.935]$ & $0.853[0.623 ; 0.943]$ \\
2015 & 18 & $0.903[0.659 ; 0.994]$ & $0.676[0.292 ; 0.863]$ & $0.820[0.528 ; 0.950]$ \\
Overall & 90 & $0.921 *$ & $0.796 *$ & $0.868 *$ \\
\hline
\end{tabular}

\footnotetext{
Notes: AHRQ: Agency for Healthcare Research and Quality; CIHI: Canadian Institute for Health Information. 95\% CI (confidence interval) was calculated based on 1000 bootstrap samples. * $95 \%$ CIs were not calculated as there is a dependency between years.
}

The results for ICC are presented in Table 5. The comparison of the AHRQ method with Sarmento et al. list showed the highest ICC of all list comparisons (ICC > 0.9 in all years), and the comparison of the AHRQ 
list with the Victorian method showed the second-highest ICC of all list comparisons. The comparisons that included the CIHI list (CIHI vs. Victorian, CIHI vs. AHRQ, and CIHI vs. Sarmento et al.) presented the lowest values of ICC in all the analyzed years; however, the CI 95\% was very broad and had no statistical significance in the two latter comparisons (CIHI vs. AHRQ and CIHI vs. Sarmento et al.).

Table 5. Comparison of Different Pairs of Lists in Terms of Information-Based Measure of Disagreement (IBMD) and Intraclass Correlation Coefficient (ICC).

\begin{tabular}{cccccc}
\hline \multicolumn{7}{c}{ CIHI vs. AHRQ } & \multicolumn{2}{c}{ CIHI vs. Victorian } \\
\hline Year & $n$ & IBMD [95\% CI] & ICC [95\% CI] & IBMD [95\% CI] & ICC [95\% CI] \\
\hline 2011 & 18 & $0.833[0.816 ; 0.844]$ & $0.604[-0.058 ; 0.852]$ & $0.815[0.799 ; 0.829]$ & $0.661[0.094 ; 0.873]$ \\
2012 & 18 & $0.837[0.826 ; 0.846]$ & $0.596[-0.080 ; 0.849]$ & $0.816[0.802 ; 0.826]$ & $0.634[0.021 ; 0.863]$ \\
2013 & 18 & $0.845[0.832 ; 0.854]$ & $0.586[-0.107 ; 0.845]$ & $0.827[0.816 ; 0.835]$ & $0.683[0.153 ; 0.882]$ \\
2014 & 18 & $0.845[0.830 ; 0.855]$ & $0.569[-0.153 ; 0.839]$ & $0.827[0.812 ; 0.840]$ & $0.677[0.138 ; 0.879]$ \\
2015 & 18 & $0.849[0.833 ; 0.860]$ & $0.477[-0.397 ; 0.805]$ & $0.833[0.818 ; 0.844]$ & $0.660[0.091 ; 0.873]$ \\
Overall & 90 & $0.842 *$ & $0.561 *$ & $0.823 *$ & $0.654 *$ \\
\hline \multicolumn{7}{c}{ * } & AHRQ vs. Victorian & AHRQ vs. Sarmento et al. \\
\hline Year & $n$ & IBMD [95\% CI] & ICC [95\% CI] & IBMD [95\% CI] & ICC [95\% CI] \\
\hline 2011 & 18 & $0.142[0.100 ; 0.185]$ & $0.904[0.744 ; 0.964]$ & $0.333[0.310 ; 0.353]$ & $0.968[0.914 ; 0.988]$ \\
2012 & 18 & $0.148[0.100 ; 0.197]$ & $0.903[0.740 ; 0.964]$ & $0.336[0.309 ; 0.352]$ & $0.960[0.893 ; 0.985]$ \\
2013 & 18 & $0.133[0.087 ; 0.183]$ & $0.918[0.781 ; 0.969]$ & $0.327[0.299 ; 0.345]$ & $0.963[0.900 ; 0.986]$ \\
2014 & 18 & $0.131[0.087 ; 0.184]$ & $0.889[0.702 ; 0.958]$ & $0.330[0.304 ; 0.352]$ & $0.968[0.915 ; 0.988]$ \\
2015 & 18 & $0.141[0.103 ; 0.187]$ & $0.864[0.636 ; 0.949]$ & $0.320[0.293 ; 0.340]$ & $0.968[0.913 ; 0.988]$ \\
Overall & 90 & $0.139 *$ & $0.898 *$ & $0.330 *$ & $0.965 *$ \\
\hline \multicolumn{7}{c}{ * } & CIHI vs. Sarmento et al. & Victorian vs. Sarmento et al. \\
\hline Year & $n$ & IBMD [95\% CI] & ICC [95\% CI] & IBMD [95\% CI] & ICC [95\% CI] \\
\hline 2011 & 18 & $0.878[0.864 ; 0.888]$ & $0.492[-0.358 ; 0.810]$ & $0.406[0.373 ; 0.436]$ & $0.895[0.719 ; 0.961]$ \\
2012 & 18 & $0.882[0.873 ; 0.888]$ & $0.482[-0.385 ; 0.806]$ & $0.421[0.387 ; 0.452]$ & $0.877[0.672 ; 0.954]$ \\
2013 & 18 & $0.886[0.876 ; 0.893]$ & $0.508[-0.315 ; 0.816]$ & $0.407[0.376 ; 0.436]$ & $0.890[0.707 ; 0.959]$ \\
2014 & 18 & $0.887[0.877 ; 0.893]$ & $0.529[-0.260 ; 0.824]$ & $0.405[0.377 ; 0.434]$ & $0.865[0.638 ; 0.949]$ \\
2015 & 18 & $0.888[0.878 ; 0.896]$ & $0.453[-0.463 ; 0.795]$ & $0.396[0.362 ; 0.426]$ & $0.853[0.606 ; 0.945]$ \\
Overall & 90 & $0.884 *$ & $0.489 *$ & $0.407 *$ & $0.878 *$ \\
\hline
\end{tabular}

Notes: AHRQ: Agency for Healthcare Research and Quality; CIHI: Canadian Institute for Health Information. ICC: Two-way mixed-effects model (average measures). ${ }^{*} 95 \%$ CIs were not calculated as there is a dependency between years.

Figure 1 is composed of six graphs that demonstrate the agreement between the pairs of lists. There is a positive slope in all graphs, indicating a positive average association between the differences in rates and the mean of rates estimated by the two lists. Thus, as the rate of avoidable hospitalizations increases, the greater the overestimation of one list seems to be in relation to the other. Moreover, in some cases (Figure 1a,b,e,f), the variability in the agreement also seems to be dependent on the mean rate of avoidable hospitalizations, being larger in districts in which the mean rate is higher and less noticeable in districts where the rate of avoidable hospitalizations is lower. However, in comparisons such as (c) or (d) of Figure 1, the variability of the differences does not seem to depend on the mean of the rates.

Another parameter that should be taken into account is the range of values regarding the difference between the two lists. When a perfect agreement is obtained, the bias between the two lists is represented by a horizontal line close to 0 . Thus, only the comparison (b) of Figure 1 seems to reach agreement in some districts with lower avoidable hospitalization rates, being also the only graph where the 0 appears in the $y$-axis. Nevertheless, for districts with larger rates, the AHRQ rate may either over- or underestimate the Victorian rate by more than 100 hospitalizations/100,000 inhabitants. The other comparisons, in general, presented a range of values regarding the differences between the lists of about hundreds of hospitalizations per 100,000 inhabitants. 


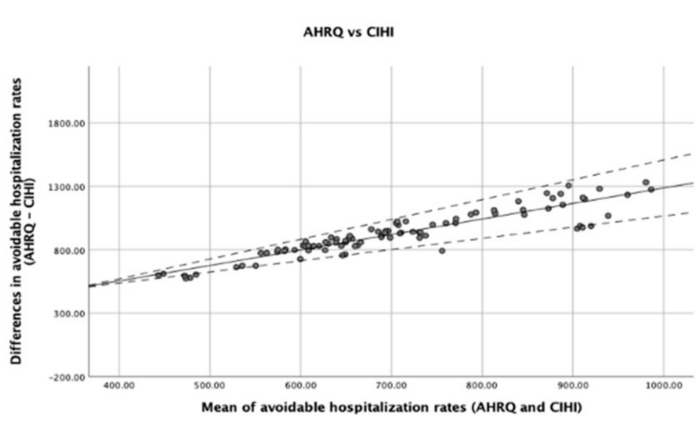

(a)

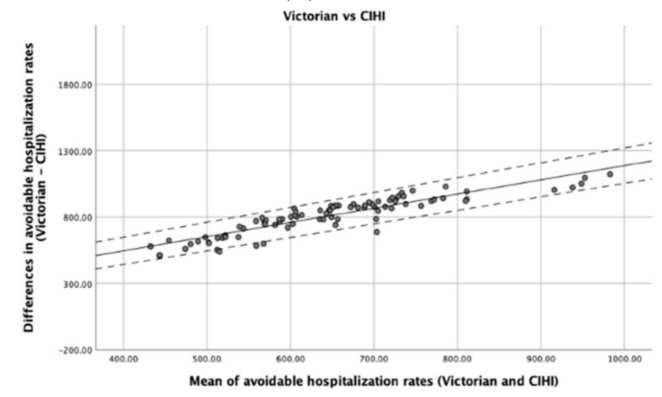

(c)

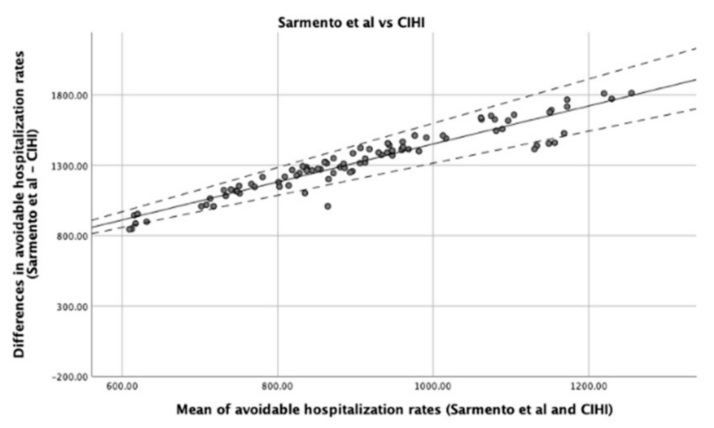

(e)

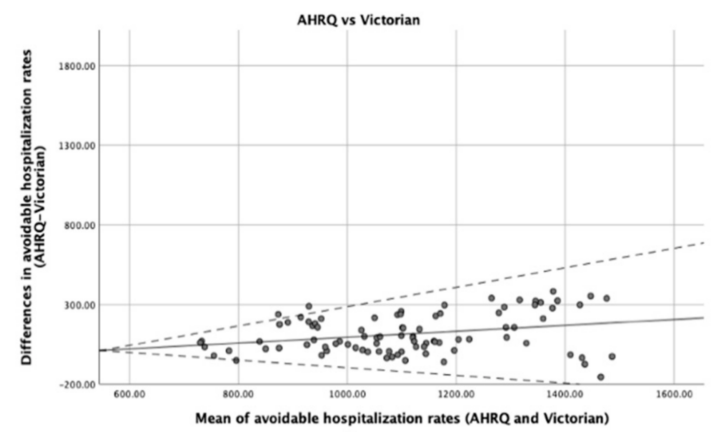

(b)

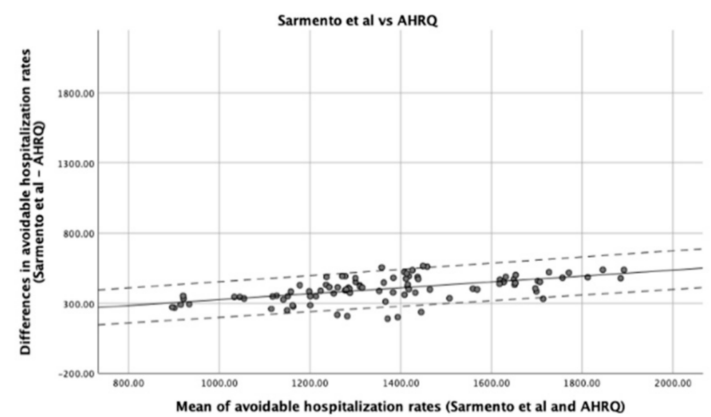

(d)

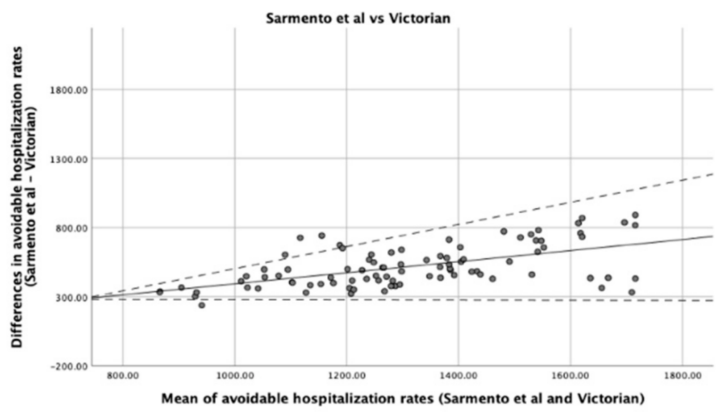

(f)

Figure 1. Bland and Altman plots comparing the agreement of different lists. (a) AHRQ vs. CIHI; (b) AHRQ vs. Victorian; (c) Victorian vs. CIHI; (d) Sarmento et al. vs. AHRQ; (e) Sarmento et al. vs. CIHI; (f) Sarmento et al. vs. Victorian. Solid line represents the difference in avoidable hospitalization rates between lists and dashed lines indicate the Bland and Altman limits of agreement.

\section{Discussion}

In this study, we identified that the AHRQ, the Victorian study, and Sarmento et al. methods showed avoidable hospitalization rates that were more similar across districts in comparison with the CIHI method, where the values found were about one-quarter or less of those found in the other lists. The AHRQ, Victoria study, and Sarmento et al. lists measured avoidable hospitalizations consistently, meaning that a positive trend over the years was identified when applying any of them, whereas a slight decrease in absolute numbers was observed when applying the CIHI list, though the percentage of avoidable hospitalizations remained stable. These results are in agreement with the findings obtained by Sarmento et al. when evaluating the Canadian method (CIHI) and the Spanish list developed by Caminal et al. [9], which was not evaluated in this work. In that study, between the years 2000 and 2012, the authors identified such discrepancies with the application of the CIHI list, as a decrease in the 
rate of avoidable hospitalizations was verified, in contrast to what was observed when applying the list proposed by Caminal et al. [26].

We obtained a considerably high correlation between all the methods; however, the correlation only allows us to conclude that the variables are associated and does not permit inferences about the agreement between them [44]. For this reason, we calculated the ICC to evaluate the reliability, and we calculated the IBMD and drew Bland and Altman plots to measure the level of agreement between lists. The comparison between the AHRQ list and the Victorian methods showed the almost highest correlation and reliability (ICC) measures and an IBMD value closer to 0. Moreover, the Bland and Altman graph revealed that some districts can have a difference close to 0 . These results are quite similar to the ones obtained for the comparison between the AHRQ and Sarmento et al. lists, although the disagreement was relatively high (IBMD $=0.330$ ) compared to the other two lists. Consequently, these two lists seem to be the ones presenting more similar results. Nevertheless, it should be noted that the different methods applied in this study clearly present specificities between them (the diseases considered ACSCs, the associated codes, and the number of cases included and excluded also determine the number of episodes that are included in each list). All of these may explain the differences found in avoidable hospitalization rates. To illustrate, the CIHI method only considers a few chronic conditions as ACSCs. Furthermore, in this method, individuals aged over 75 years old are excluded, and it is known that age is an important factor associated with hospitalization for ACSCs, as chronic conditions are more prevalent in older populations [25], which might explain the lower rates of ACSCs obtained by this list in comparison with the other methodologies. Additionally, it also suggests that the prevalence of chronic conditions associated with avoidable hospitalizations that are included in the CIHI list is stable across the years under study. These reasons may also justify the inverse trend in avoidable hospitalizations compared to the other methods, since all hospitalizations due to acute illness are not counted. This leads us to believe that acute hospitalizations may have a considerable influence on avoidable hospitalization rates.

Moreover, different lists can have distinct purposes; for instance, the lists that cover more chronic diseases focus essentially on the management of primary health care, whereas other lists, such as the Victorian method, can be more comprehensive, including acute and immunizable diseases, and for that reason tend to identify a higher number of hospitalizations. Nevertheless, to counteract these limitations, the construction of an international list would bring advantages regarding comparative purposes; to achieve this goal, the health indicator should cover the same codes related to a specific disease, according to Nedel et al. [45].

Our findings show that avoidable hospitalizations increased in Portugal when considering the lists that included acute and chronic ACSCs and decreased with the list that only includes chronic ACSCs, though rates remained stable. Rosano et al. compared hospitalizations of ACSCs in Italy and Germany and verified that avoidable admissions accounted for $8 \%$ and $11 \%$ of total admissions, respectively, using the conditions defined by Pirani et al. and the criteria defined by Weissman et al., between the years 2000/2001 and 2008 [46], with the percentages of the hospitalizations due to ACSCs not differing much from those found in our study. Rosano et al. also verified that, in Italy, the chronic conditions decreased by about $23 \%$, in contrast to the acute conditions, which remained stable. On the other hand, the hospitalizations due to ACSCs in Germany increased for both conditions. In an ecological study that compared the potentially avoidable hospitalizations in five European countries (Portugal, Denmark, Spain, England, and Slovenia) through six chronic conditions, the rates in 2009 varied from 93.7 cases per 10,000 inhabitants in Denmark to 34.8 cases per 10,000 inhabitants in Portugal. The authors also concluded that a variation within-country was presented and the rates remained stable throughout the period analyzed, except for in England and Denmark where rates decreased [16]. These findings are similar to ours regarding the application of the CIHI list that similarly only includes chronic conditions, and the rates seemed to be stable across the years.

When comparing our results of ACSC rates to those of other similar international studies in the literature, we must be aware that the comparison should be analyzed with caution or even avoided 
if the list applied was not the same, also considering the fact that the health context itself differs. Likewise, some authors $[10,47]$ state that the inconsistency of codes and diseases used by different methodologies hampers the comparison between geographical areas, as well as a wider and broader utilization of the indicator. However, there are also advantages of validating a list of ACSCs according to the health context of a given population (or country), since it increases the specificity of the list, which is more suitable for primary health care in that specific health context [26]. A work by the World Health Organization [48] on the evaluation of the provision of health services according to hospitalizations by ACSCs stated that the list developed by Bardsley et al. [49] was the most robust generic non-country-specific list of ACSCs.

Nevertheless, studies that address comparisons between countries considered that the avoidable hospitalization rates seem to be lower in those with stronger primary health care [50]. This reinforces the idea that hospitalizations by ACSCs can be avoided, essentially by good primary health care services. However, in high-income countries, geographic variations are relatively common and can represent variable quality of care and inefficient use of resources [19]. Some studies have already identified several factors that could explain the variation of the avoidable hospitalization rates within countries. Particularly in Portugal, Carneiro et al. showed a statistically significant association between the rates of hospitalizations due to ACSCs and the proportion of the population with family physicians and travel time to the provider. Additionally, despite not being statistically relevant, areas with individuals with lower education and with lower income presented higher ACSC hospitalization rates [51]. Another study carried out in Portugal found that the population density was lower for municipalities with a higher risk of hospitalizations for ACSCs (acute and chronic conditions). Considering acute diseases only, the municipalities that had a higher risk of hospitalization due to ACSCs had a higher mean proportion of elderly people, a higher proportion of people living in rural areas, and a low education level [31]. These factors were also identified in studies conducted in other countries [16,19].

\section{Limitations and Strengths}

We assessed the avoidable hospitalizations in Portugal through four different methodologies, providing different rates of avoidable hospitalizations regarding the list applied. We also adjusted the rates for age and sex to account for age differences in geographic distribution and possibly different disease prevalence being present, which increased the fairness of the comparison between districts. Still, we did not adjust our results to other factors that could yet influence the obtained rates and more final insights regarding the performance of regional providers, such as economic and educational factors and the distance faced by some populations in travel to primary care facilities.

This study was performed with data from mainland Portugal and only included hospitalizations occurring in public hospitals; therefore, other episodes of ACSC hospitalizations may have occurred in private hospitals during the studied period.

The list developed by Sarmento et al. adapted to the Portuguese context was originally defined with ICD-10 codes; however, to convert to ICD-9-CM codes, we first performed an approximation to ICD-10-CM codes using the first three or four ICD-10 characters, and the approximate matches were then mapped to ICD-9-CM using the GEMs method, which in turn may have resulted in some codes being slightly different from the codes defined in the original list.

\section{Conclusions}

Of all the studied lists, those that seemed to demonstrate a greater agreement were the list proposed by Sarmento et al. compared to the AHRQ list and the AHRQ method compared to the Victorian list. Despite the results found, the choice of a list should always take into account the health context of the study population as well as the diseases included in the list, as these factors impede the replacement of one list by another. Nevertheless, it is important to state that we should compare comparable indicators and ACSC lists cannot be used interchangeably. 
Author Contributions: Conceptualization and study design, J.V.S., J.V. and A.F.; methods, A.P., J.V.S., J.S., J.V., C.C.S. and A.F.; validation, M.L. and J.S.; formal analysis, A.P., M.L., J.S., J.V.S.; writing-original draft preparation, A.P.; writing-review and editing, A.P., M.L., J.S., J.V.S., J.V., C.C.S. and A.F.; supervision, A.F.; funding acquisition, A.F., J.V. and J.V.S. All authors have read and agreed to the published version of the manuscript.

Funding: The authors disclosed receipt of the following financial support for the research, authorship, and/or publication of this article: This work was financed by FEDER-Fundo Europeu de Desenvolvimento Regional funds through the COMPETE 2020-Operacional Programme for Competitiveness and Internationalisation (POCI) and by Portuguese funds through FCT-Fundação para a Ciência e a Tecnologia in the framework of the project POCI-01-0145-FEDER-030766 ("1st.IndiQare-Quality indicators in primary health care: validation and implementation of quality indicators as an assessment and comparison tool").

Acknowledgments: The authors would like to thank Administração Central do Sistema da Saúde, I.P. for providing the hospital discharge data of public hospitals.

Conflicts of Interest: The authors declare no conflict of interest.

\section{References}

1. Billings, J.; Zeitel, L.; Lukomnik, J.; Carey, T.S.; Blank, A.E.; Newman, L. Impact of socioeconomic status on hospital use in New York City. Health Aff. (Millwood) 1993, 12, 162-173. [CrossRef] [PubMed]

2. Manderbacka, K.; Arffman, M.; Satokangas, M.; Keskimäki, I. Regional variation of avoidable hospitalisations in a universal health care system: A register-based cohort study from Finland 1996-2013. BMJ Open 2019, 9, e029592. [CrossRef] [PubMed]

3. Caminal, J.; Starfield, B.; Sanchez, E.; Casanova, C.; Morales, M. The role of primary care in preventing ambulatory care sensitive conditions. Eur. J. Public Health 2004, 14, 246-251. [CrossRef] [PubMed]

4. Rosano, A.; Loha, C.A.; Falvo, R.; van der Zee, J.; Ricciardi, W.; Guasticchi, G.; de Belvis, A.G. The relationship between avoidable hospitalization and accessibility to primary care: A systematic review. Eur. J. Public Health 2013, 23, 356-360. [CrossRef] [PubMed]

5. Rizza, P.; Bianco, A.; Pavia, M.; Angelillo, I.F. Preventable hospitalization and access to primary health care in an area of Southern Italy. BMC Health Serv. Res. 2007, 7, 134. [CrossRef]

6. Ansari, Z. The Concept and Usefulness of Ambulatory Care Sensitive Conditions as Indicators of Quality and Access to Primary Health Care. Aust. J. Prim. Health 2007, 13, 91-110. [CrossRef]

7. Solberg, L.I.; Peterson, K.E.; Ellis, R.W.; Romness, K.; Rohrenbach, E.; Thell, T.; Smith, A.; Routier, A.; Stillmank, M.W.; Zak, S. The Minnesota project: A focused approach to ambulatory quality assessment. Inquiry (Oslo) 1990, 27, 359-367.

8. Weissman, J.S.; Gatsonis, C.; Epstein, A.M. Rates of avoidable hospitalization by insurance status in Massachusetts and Maryland. JAMA 1992, 268, 2388-2394. [CrossRef] [PubMed]

9. Caminal, J.; Mundet, X.; Ponsà, J.A.; Sánchez, E.; Casanova, C. Las hospitalizaciones por ambulatory care sensitive conditions: Selección del listado de códigos de diagnóstico válidos para España. Gac. Sanit. 2001, 15, 128-141. [CrossRef]

10. Purdy, S.; Griffin, T.; Salisbury, C.; Sharp, D. Ambulatory care sensitive conditions: Terminology and disease coding need to be more specific to aid policy makers and clinicians. Public Health 2009, 123, 169-173. [CrossRef]

11. Sundmacher, L.; Fischbach, D.; Schuettig, W.; Naumann, C.; Augustin, U.; Faisst, C. Which hospitalisations are ambulatory care-sensitive, to what degree, and how could the rates be reduced? Results of a group consensus study in Germany. Health Policy 2015, 119, 1415-1423. [CrossRef] [PubMed]

12. Canadian Insititute for Health Information. Health Indicators 2008. Ottawa, ON, Canada. 2008. Available online: http://indicatorlibrary.cihi.ca/display/HSPIL/Ambulatory+Care+Sensitive+Conditions (accessed on 1 May 2020).

13. Agency for Healthcare Research and Quality. Prevention Quality Indicators Overview 2018. Available online: https://www.qualityindicators.ahrq.gov/Archive/PQI_TechSpec_ICD09_v60.aspx (accessed on 1 May 2020).

14. Ansari, Z.; Haider, S.I.; Ansari, H.; de Gooyer, T.; Sindall, C. Patient characteristics associated with hospitalisations for ambulatory care sensitive conditions in Victoria, Australia. BMC Health Serv. Res. 2012, 12, 475. [CrossRef]

15. Pirani, M.; Schifano, P.; Agabiti, N.; Davoli, M.; Caranci, N.; Perucci, C.A. Potentially avoidable hospitalisation in Bologna, 1997-2000: Temporal trend and differences by income level. Epidemiol. Prev. 2006, 30, 169-177. [PubMed] 
16. Thygesen, L.C.; Christiansen, T.; Garcia-Armesto, S.; Angulo-Pueyo, E.; Martinez-Lizaga, N.; Bernal-Delgado, E. Potentially avoidable hospitalizations in five European countries in 2009 and time trends from 2002 to 2009 based on administrative data. Eur. J. Public Health 2015, 25 (Suppl. S1), 35-43. [CrossRef]

17. Alfradique, M.E.; Bonolo, P.D.F.; Dourado, I.; Lima-Costa, M.F.; Macinko, J.; Mendonça, C.S.; Oliveira, V.B.; Sampaio, L.F.R.; De Simoni, C.; Turci, M.A. Internações por condições sensíveis à atenção primária: A construção da lista brasileira como ferramenta para medir o desempenho do sistema de saúde (Projeto ICSAP-Brasil). Cad. Saude Publica 2009, 25, 1337-1349. [CrossRef] [PubMed]

18. Weeks, W.B.; Ventelou, B.; Paraponaris, A. Rates of admission for ambulatory care sensitive conditions in France in 2009-2010: Trends, geographic variation, costs, and an international comparison. Eur. J. Health Econ. 2016, 17, 453-470. [CrossRef]

19. Busby, J.; Purdy, S.; Hollingworth, W. A systematic review of the magnitude and cause of geographic variation in unplanned hospital admission rates and length of stay for ambulatory care sensitive conditions. BMC Health Serv. Res. 2015, 15, 324. [CrossRef]

20. Satokangas, M.; Lumme, S.; Arffman, M.; Keskimäki, I. Trajectory modelling of ambulatory care sensitive conditions in Finland in 1996-2013: Assessing the development of equity in primary health care through clustering of geographic areas-an observational retrospective study. BMC Health Serv. Res. 2019, 19, 629. [CrossRef]

21. Agabiti, N.; Pirani, M.; Schifano, P.; Cesaroni, G.; Davoli, M.; Bisanti, L.; Caranci, N.; Costa, G.; Forastiere, F.; Marinacci, C.; et al. Income level and chronic ambulatory care sensitive conditions in adults: A multicity population-based study in Italy. BMC Public Health 2009, 9, 457. [CrossRef]

22. Brown, A.; Goldacre, M.; Hicks, N.; Rourke, J.; McMurtry, R.; Brown, J.; Anderson, G. Hospitalization for Ambulatory Care-Sensitive Conditions: A Method for Comparative Access and Quality Studies Using Routinely Collected Statistics. Can. J. Public Health 2001, 92, 155-159. [CrossRef]

23. Caminal Homar, J.; Morales Espinoza, M.; Sanchez Ruiz, E.; Cubells Larrosa, M.J.; Bustins Poblet, M. Hospitalizations preventable by timely and effective primary health care. Aten. Primaria 2003, 31, 6-14. [CrossRef]

24. McMillan, S.S.; King, M.; Tully, M.P. How to use the nominal group and Delphi techniques. Int. J. Clin. Pharm. 2016, 38, 655-662. [CrossRef] [PubMed]

25. Rocha, J.V.M.; Sarmento, J.; Moita, B.; Marques, A.P.; Santana, R. Comparative research aspects on hospitalizations for ambulatory care sensitive conditions: The case of Brazil and Portugal. Cien. Saude Colet. 2020, 25, 1375-1388. [CrossRef]

26. Sarmento, J.; Alves, C.; Oliveira, P.; Sebastiao, R.; Santana, R. Characterization and Evolution of Avoidable Admissions in Portugal: The Impact of Two Methodologic Approaches. Acta Med. Port. 2015, 28, 590-600. [CrossRef]

27. Bourret, R.; Mercier, G.; Mercier, J.; Jonquet, O.; De La Coussaye, J.E.; Bousquet, P.J.; Robine, J.M.; Bousquet, J. Comparison of two methods to report potentially avoidable hospitalizations in France in 2012: A cross-sectional study. BMC Health Serv. Res. 2015, 15, 4. [CrossRef]

28. Instituto Nacional de Estatística. População Residente (N. ${ }^{\circ}$ ) por Local de Residência (NUTS-2013), Sexo e Grupo Etário; Anual. 2020. Available online: https://www.ine.pt/xportal/xmain?xpid=INE\&xpgid=ine_ indicadores\&indOcorrCod=0008273\&contexto=bd\&selTab=tab2 (accessed on 11 May 2020).

29. Public Health Rural and Regional Health and Aged Care Services Division, Victorian Government Department of Human Services. The Victorian Ambulatory Care Sensitive Conditions Study Report 2001-2002; Public Health Rural and Regional Health and Aged Care Services Division, Victorian Government Department of Human Services: Melbourne, Australia, 2004.

30. Sarmento, J.; Rocha, J.V.M.; Santana, R. Defining ambulatory care sensitive conditions for adults in Portugal. BMC Health Serv. Res. 2020, 20, 754. [CrossRef]

31. Rocha, J.V.M.; Nunes, C.; Santana, R. Avoidable hospitalizations in Brazil and Portugal: Identifying and comparing critical areas through spatial analysis. PLoS ONE 2019, 14, e219262. [CrossRef]

32. Dimitrovova, K.; Costa, C.; Santana, P.; Perelman, J. Evolution and financial cost of socioeconomic inequalities in ambulatory care sensitive conditions: An ecological study for Portugal, 2000-2014. Int. J. Equity Health 2017, 16, 145. [CrossRef] 
33. Sentell, T.L.; Ahn, H.J.; Miyamura, J.; Juarez, D.T. Cost Burden of Potentially Preventable Hospitalizations for Cardiovascular Disease and Diabetes for Asian Americans, Pacific Islanders, and Whites in Hawai'i. J. Health Care Poor Underserved 2015, 26, 63-82. [CrossRef]

34. Manzoli, L.; Flacco, M.E.; De Vito, C.; Arca, S.; Carle, F.; Capasso, L.; Marzuillo, C.; Muraglia, A.; Samani, F.; Villari, P. AHRQ prevention quality indicators to assess the quality of primary care of local providers: A pilot study from Italy. Eur. J. Public Health 2014, 24, 745-750. [CrossRef]

35. Galarraga, J.E.; Mutter, R.; Pines, J.M. Costs associated with ambulatory care sensitive conditions across hospital-based settings. Acad. Emerg. Med. 2015, 22, 172-181. [CrossRef]

36. Schiotz, M.; Price, M.; Frolich, A.; Sogaard, J.; Kristensen, J.K.; Krasnik, A.; Ross, M.N.; Diderichsen, F.; Hsu, J. Something is amiss in Denmark: A comparison of preventable hospitalisations and readmissions for chronic medical conditions in the Danish Healthcare system and Kaiser Permanente. BMC Health Serv. Res. 2011, 11, 347. [CrossRef]

37. Santos, J.V.; Viana, J.; Devleeschauwer, B.; Haagsma, J.; Santos, C.; Ricciardi, W.; Freitas, A. Health expectancies in the European Union: Same concept, different methods, different results. J. Epidemiol. Community Health 2020. in peer review.

38. Akoglu, H. User's guide to correlation coefficients. Turk. J. Emerg. Med. 2018, 18, 91-93. [CrossRef]

39. Field, A. Discovering Statistics Using IBM SPSS Statistics; SAGE Publications: Thousand Oaks, CA, USA, 2009.

40. Koo, T.K.; Li, M.Y. A Guideline of Selecting and Reporting Intraclass Correlation Coefficients for Reliability Research. J. Chiropr. Med. 2016, 15, 155-163. [CrossRef]

41. Henriques, T.; Antunes, L.; Bernardes, J.; Matias, M.; Sato, D.; Costa-Santos, C. Information-based measure of disagreement for more than two observers: A useful tool to compare the degree of observer disagreement. BMC Med. Res. Methodol. 2013, 13, 47. [CrossRef]

42. Bland, J.M.; Altman, D.G. Agreement between methods of measurement with multiple observations per individual. J. Biopharm. Stat. 2007, 17, 571-582. [CrossRef]

43. Kottner, J.; Audigé, L.; Brorson, S.; Donner, A.; Gajewski, B.J.; Hróbjartsson, A.; Roberts, C.; Shoukri, M.; Streiner, D.L. Guidelines for Reporting Reliability and Agreement Studies (GRRAS) were proposed. J. Clin. Epidemiol. 2011, 64, 96-106. [CrossRef] [PubMed]

44. Hirakata, V.; Camey, S. Análise de Concordância entre Métodos de Bland-Altman. Rev. HCPA 2009, 29, $261-268$.

45. Nedel, F.B.; Facchini, L.A.; Bastos, J.L.; Martín-Mateo, M. Conceptual and methodological aspects in the study of hospitalizations for ambulatory care sensitive conditions. Cien. Saude Colet. 2011, 16, 1145-1154. [CrossRef] [PubMed]

46. Rosano, A.; Peschel, P.; Kugler, J.; Ricciardi, W.; Guasticchi, G.; van der Zee, J. Preventable hospitalization and the role of primary care: A comparison between Italy and Germany. J. Public Health (Oxf.) 2013, 21, 445-454. [CrossRef]

47. Gibbons, D.C.; Bindman, A.B.; Soljak, M.A.; Millett, C.; Majeed, A. Defining primary care sensitive conditions: A necessity for effective primary care delivery? J. R. Soc. Med. 2012, 105, 422-428. [CrossRef]

48. World Health Organization. Assessing Health Services Delivery Performance with Hospitalizations for Ambulatory Care Sensitive Conditions; WHO Regional Office for Europe: Copenhagen, Denmark, 2016.

49. Bardsley, M.; Blunt, I.; Davies, S.; Dixon, J. Is secondary preventive care improving? Observational study of 10-year trends in emergency admissions for conditions amenable to ambulatory care. BMJ Open 2013, 3, e002007. [CrossRef]

50. Kringos, D.; Boerma, W.; Bourgueil, Y.; Cartier, T.; Dedeu, T.; Hasvold, T.; Hutchinson, A.; Lember, M.; Oleszczyk, M.; Pavlic, D.R.; et al. The strength of primary care in Europe: An international comparative study. Br. J. Gen. Pract. 2013, 63, e742-e750. [CrossRef]

51. Carneiro, C.S. Hospitalisation of ambulatory care sensitive conditions and access to primary care in Portugal. Public Health 2018, 165, 117-124. [CrossRef]

Publisher's Note: MDPI stays neutral with regard to jurisdictional claims in published maps and institutional affiliations. 